\title{
Status of Bariatric Surgery in Germany - Results of the Nationwide Survey on Bariatric Surgery 2005-2007
}

\author{
Christine Stroh $^{\mathrm{a}, \mathrm{z}}$ Dieter Birk ${ }^{\mathrm{b}}$ Ricarda Flade-Kuthe ${ }^{\mathrm{c}} \quad$ Michael Frenken $^{\mathrm{d}}$ Beate Herbig ${ }^{\mathrm{e}}$ \\ Stefan Höhne $^{f}$ Hinrich Köhler ${ }^{g}$ Volker Lange ${ }^{h}$ Kaja Ludwig $^{i}$ Ralf Matkowitz ${ }^{j}$ \\ Günther Meyer $^{\mathrm{k}}$ Frank Meyer $^{\mathrm{v}}$ Peter Pick $^{\mathrm{l}}$ Thomas Horbach $^{\mathrm{m}, \mathrm{x}}$ Stefan Krause \\ Lothar Schäfer $^{\circ} \quad$ Matthias Schlensak $^{p}$ Edward Shah ${ }^{q}$ Thomas Sonnenberg $^{r}$ \\ Martin Susewind ${ }^{\mathrm{s}}$ Hans Voigt $^{\mathrm{t}}$ Rudolf A. Weiner ${ }^{\mathrm{u}}$ Stefanie Wolff $^{\mathrm{v}, \mathrm{z}}$ Hans Lippert ${ }^{\mathrm{v}, \mathrm{z}}$ \\ Anna Maria Wolf ${ }^{\mathrm{w}}$ Uwe Schmidt ${ }^{\mathrm{y}}$ Thomas Manger ${ }^{\mathrm{a}, \mathrm{z}}$ Working Group Bariatric Surgery

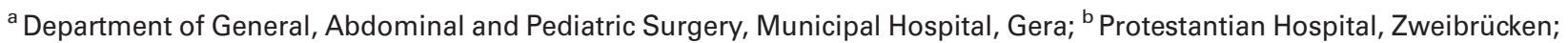 \\ ${ }^{\mathrm{c}}$ Hospital DRK Clementinenhaus, Hanover; ${ }^{\mathrm{d}}$ St.-Josef Hospital, Monheim; ${ }^{\mathrm{e}}$ Hospital Diakonissenhaus, Hamburg - Alten Eichen; \\ ${ }^{f}$ Hospital Burglengenfeld; ${ }^{g}$ Hospital Herzogin-Heim, Brunswick; ${ }^{\text {h }}$ Schlosspark-Hospital, Berlin; i Municipal Hospital Rostock South, Rostock; \\ ${ }^{j}$ Surgical Department and Bariatric Center, Frankfurt/M.; ${ }^{k}$ Surgical Department, Hospital Munich-Bogenhausen, Munich; \\ 'Aesculap-West Clinic, Hamburg; ${ }^{m}$ Department of Surgery, Friedrich-Alexander University, Erlangen-Nuremberg; \\ ${ }^{\mathrm{n}}$ Hospital Tönning, Tönning; ${ }^{\circ}$ Hospital Waldkirchen, Waldkirchen; ${ }^{\mathrm{P}}$ Protestantian Hospital, Dinslaken; \\ ${ }^{\mathrm{q}}$ Department of Surgery, University Hospital, Mannheim; ' Dominikus Hospital Düsseldorf; ${ }^{\mathrm{s}}$ MIC Clinic Berlin; \\ ${ }^{\mathrm{t}}$ St.-Vinzenz Hospital, Hanau; ${ }^{\mathrm{u}}$ Hospital Sachsenhausen, Frankfurt/M.; ${ }^{\vee}$ Department of Surgery, University Hospital, Magdeburg; \\ ${ }^{\mathrm{w}}$ Department of Surgery, University Hospital, UIm; ${ }^{\mathrm{X}}$ Municipal Hospital, Schwabach; ${ }^{\vee}$ StatConsult, Magdeburg; \\ ${ }^{z}$ Institute of Quality Assurance in Surgery at the Otto-von-Guericke University, Magdeburg, Germany
}

\section{Key Words}

Bariatric surgery · Gastric banding · Sleeve gastrectomy · Gastric bypass - Biliopancreatic diversion - German multicenter trial

\section{Summary}

Background: Most studies on bariatric surgery outcomes are performed as clinical trials or reflect the clinical experience in single centers. The status of bariatric surgery in Germany has been examined with the cooperation of clinics and hospitals at the Institute of Quality Assurance in Surgery at the Ottovon-Guericke University of Magdeburg (Germany) since January 1, 2005. Methods: In this prospective multicenter observational study, the data obtained for all primary bariatric procedures, including all repeated operations, performed on consecutive patients with morbid obesity at participating hospitals from 2005 to 2007 were prospectively collected using an internet online data registry. Perioperative characteristics such as the spectrum of diagnostic measurements, type of surgical procedures, and short- and long-term outcomes were investigated. Results: During the study period 3,123 surgical procedures were performed. In 2005 and 2006, gastric banding (GB) was the operation performed most frequently, followed by the Roux-en-Y gastric bypass (RYGBP). In 2007, a RYGBP was carried out in $42.1 \%$ of all bariatric procedures. Among all patients, $74.4 \%$ were female. The mean BMI ranged from $48.5 \mathrm{~kg} / \mathrm{m}^{2}$ in 2005 to $48.0 \mathrm{~kg} / \mathrm{m}^{2}$ in 2007 . Follow-up data after 12 months were available for $63.8 \%$ of the patients operated in 2005 and 2006. The mortality was $0.1 \%$ (30 days) and $0.16 \%$ (overall). Conclusion: As indicated by the worldwide trend, there is an ongoing change from GB to sleeve gastrectomy (SG) and malabsorptive procedures. The BMI of German bariatric surgical patients is substantially higher than that of patients from most other countries. There were no differences in overall outcomes during follow-up as compared to published studies.

\section{Introduction}

Internationally, Germany is among the countries with a very high prevalence of obesity. Germany has the highest prevalence of obesity in Europe. The German Health Survey data from 2003 indicate that the prevalence of obesity is $60 \%$, with $70 \%$ of men and $50 \%$ of women being obese [1].

$\begin{array}{ll}\text { KARGER } & \text { ( 2009 S. Karger GmbH, Freiburg } \\ \text { Fax +497614520714 } & \text { Accessible online at: } \\ \begin{array}{l}\text { E-mail Information@Karger.de } \\ \text { www.karger.com }\end{array} & \text { www.karger.com/ofa }\end{array}$


Particularly in Germany, the health insurance agencies are concerned about the outcome of obesity surgery. From an ethical point of view, an investigation on amelioration of comorbidities after different bariatric procedures has to be conducted in observational or cohort studies [2,3]. Most studies to date have either been performed in the context of open clinical trials (e.g. Swedish Obesity Subject study, SOS) or they reflect the clinical experience of specific centers [4-6].

The German Society of Surgery and the German Society of Surgery of Obesity initiated the present prospective study. The aims of this multicenter observational study were to evaluate daily practice in bariatric surgery in Germany in order to evaluate the long-term complications after various bariatric procedures, and thus assess the quality of obesity surgery. The registered cohort of 3,122 patients has been studied since 2005. Information on surgical technique, surgical complications, and mortality was collected. Follow-up data after more than 12 months were available for 929 patients. Outcome measures characterize the effect of bariatric surgery on weight loss and amelioration of comorbidities [7].

\section{Material and Methods}

The ongoing German multicenter observational study was initiated as a means of quality assurance in obesity surgery on January 1, 2005 [8]. The data were collected prospectively at surgical departments and hospitals throughout Germany using an online data bank. In the trial, primary bariatric operations as well as revisional procedures were registered. Long-term complications were documented in patients who underwent primary bariatric surgery before January 1, 2005.

Prior to enrollment, each patient signed a consent form. The study was conducted according to the recommendations of the Declaration of Helsinki for Biomedical Research and the guidelines and standards of the Institutional Review Boards.

Follow-up data about weight loss, amelioration of comorbidities, and longterm complications were collected annually.

\section{Results}

The data of the German multicenter observational study for quality assurance in obesity surgery was obtained during the study period from 2005 to 2007 . The number of hospitals participating every year is shown in table 1. Hospitals that took part in the voluntary multicenter trial are shown in figure 1.

Over the years there was a varying distribution of hospitals and centers that provide bariatric surgery in the various regions of Germany (table 2). During the same period, the number of hospitals performing $>50$ bariatric procedures per year continued to increase (fig. 2).

In total, $818(26.2 \%)$ men and 2,304 (73.8\%) women were enrolled in the study. Demographic data of these patients are shown in table 3. From 2005 to 2007, there were no significant changes in the demographics of the cohort (age: $p=0.059$; BMI: $p=0.525$; weight: $\mathrm{p}=0.829$; height: $\mathrm{p}=0.715$ ).
Table 1. Number of hospitals participating in the study and their enrolled patients over the years

\begin{tabular}{lllr}
\hline Year & \multicolumn{2}{c}{ Hospitals } & \multirow{2}{*}{ Patients } \\
\cline { 2 - 3 } & Announcing & Active participation & \\
\hline 2005 & 66 & 21 & 629 \\
2006 & 77 & 32 & 827 \\
2007 & 82 & 35 & 1,666 \\
Total (2005-2007) & & & 3,122 \\
\hline
\end{tabular}

During the analyzed study period, $<20 \%$ of the patients did not suffer from any comorbidity. Regarding the comorbidities, no significant differences were found when comparing the years 2005 , 2006, and 2007 ( $p>0.005)$ (table 4).

The most frequent operation performed in 2005 and 2006 was gastric banding (GB). In 2007, more Roux-en-Y gastric bypass (RYGBP) procedures were carried out. The annual frequency of each surgical procedure is shown in figure 3.

In total, 1,113 GB operations were performed. The laparoscopic approach was used in $95.6 \%$ of the cases. The overall rate of conversion was $0.7 \%$.

Since 2006 sleeve gastrectomy (SG) has become a more accepted operation in Germany. In 2006, only 16 SG surgeries were documented in the quality assurance study registry, whereas 122 isolated SG operations were performed in 2007. The laparoscopic technique was the predominant one carried out in $97.6 \%$ of the patients with a $0 \%$ conversion rate. The hospital volume per hospital ranged from 1-67; only 3 hospitals performed $>10$ operations in 2007.

In 2005, RYGBP was performed in $43.8 \%$ of all bariatric operations (2006: $34.2 \%$, 2007: 42.1\%). The laparoscopic approach was the preferred operative technique, accounting for $93.5 \%$ of all RYGBP operations. During subsequent time periods, the proportion of surgeries utilizing the laparoscopic approach increased significantly from $88.9 \%$ in 2005 to $95.9 \%$ in 2007 ( $p<0.001)$. The conversion rate was $1.5 \%$ over the entire 3 -year period.

In Germany, biliopancreatic diversion (BPD) $(n=61)$ was performed in only 3 hospitals participating in this study. The majority of the operations were carried out laparoscopically. In 2006, BPD was achieved by laparotomy at only 1 hospital.

Duodenal Switch (DS) as a bariatric procedure was performed in 5 hospitals. Surgeons in only 3 of the 5 hospitals performed DS using a laparoscopic approach.

From 2005 to 2007 , the postoperative mortality was $0.16 \%$. 2 patients died of rhabdomyolysis (RML), a third patient developed pneumonia following leakage of the staple line after SG, 2 patients died postoperatively after 30 days. Both developed anastomotic insufficiency. Hence, 30 -day mortality was $0.1 \%$.

One-year follow-up data were available for $63.8 \%(n=1,456)$ of the study patients. There were no demographic differences between this subset and the entire study population. The extent of BMI reduction by bariatric procedure among this subset of patients is shown in table 5. Compared to restrictive operations, the $\mathrm{BMI}$ reduction was significantly greater after malabsorptive procedures. 


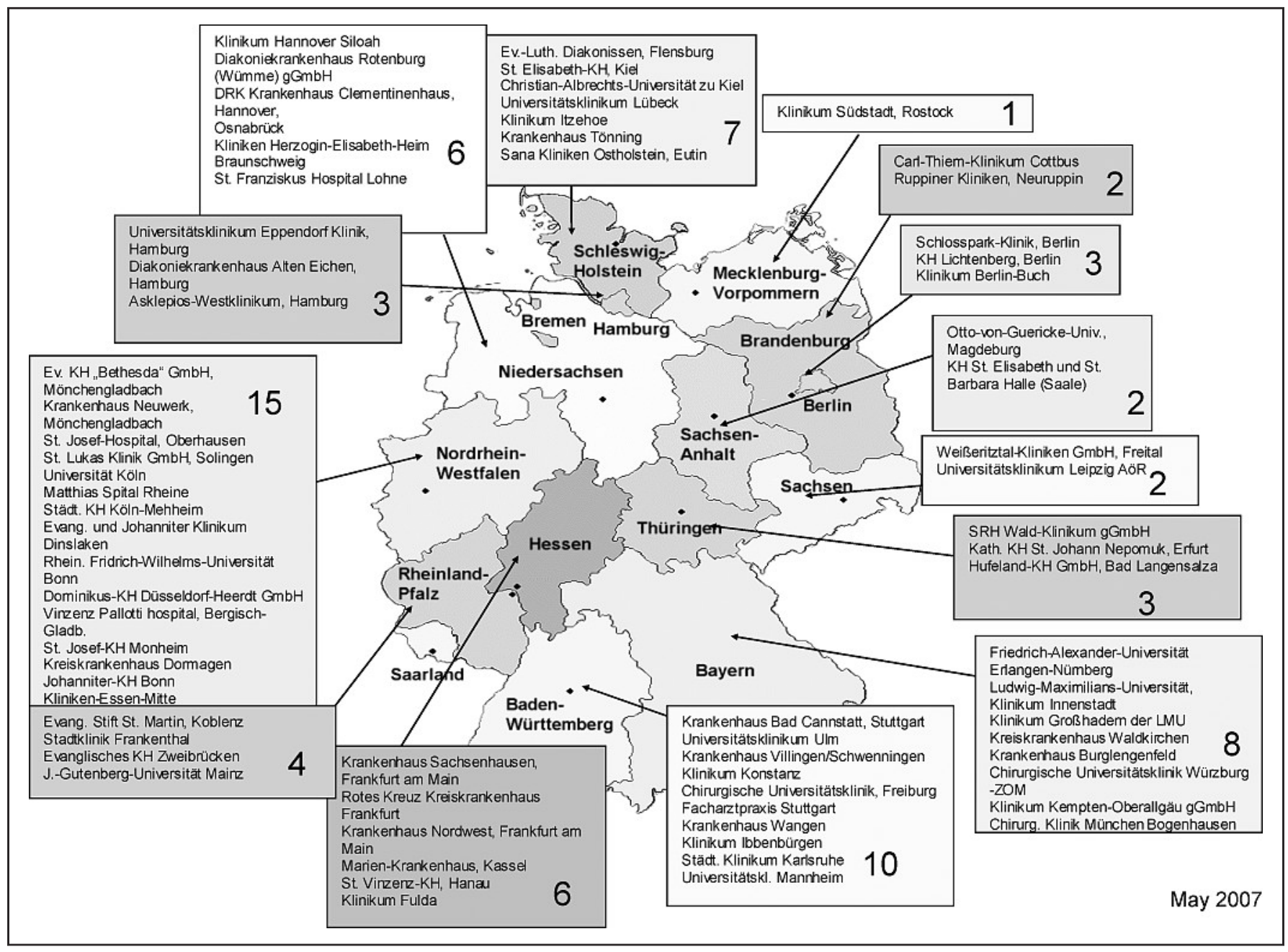

Fig. 1. Participating hospitals in the German Trial on Quality Assurance in Bariatric Surgery.

\section{Discussion}

Internationally, Germany is a country with a high prevalence of morbid obesity and the highest prevalence of obesity in Europe. Yet, due to the difficulties of covering bariatric surgery by health insurance, the rate of bariatric operations in Germany is the smallest with among the USA and other European countries. In order to provide bariatric surgery in Germany and to estimate the actual situation of bariatric surgery, the German Study on Quality Assurance in Bariatric Surgery was initiated [8].

The aim of the nationwide multicenter observational study is a systematic analysis of perioperative characteristics, factors, and parameters that impact the surgical and general outcomes, including long-term complications, in current clinical practice.

The advantage of the prospective German multicenter observational study for quality assurance in obesity surgery is that it limits biases such as regional, socioeconomic, voluntary, and center effects. In the present study, the cohort assessed is clearly representative of the general German population. Specific hospital conditions may account for the different numbers of bariatric operations performed in different regions. Only 7 centers had more than 50 patients per year. There is an ongoing trend to develop bariatric sur-
Table 2. Distribution of bariatric surgeries from 2005 to 2007 by Germany federal state

\begin{tabular}{lrrr}
\hline & \multicolumn{3}{c}{ Number of bariatric operations } \\
\cline { 2 - 4 } & 2005 & 2006 & 2007 \\
\hline Baden-Württemberg & 17 & 8 & 92 \\
Bavaria & 91 & 120 & 210 \\
Berlin & 0 & 8 & 89 \\
Brandenburg & 12 & 8 & 0 \\
Hamburg & 48 & 66 & 90 \\
Hesse & 325 & 309 & 725 \\
Lower Saxony & 52 & 68 & 78 \\
Mecklenburg-Western Pomerania & 15 & 4 & 0 \\
Northrhine-Westfalia & 20 & 91 & 130 \\
Rhineland-Palatinate & 0 & 18 & 29 \\
Saxony & 0 & 1 & 0 \\
Saxony-Anhalt & 17 & 14 & 17 \\
Schleswig-Holstein & 0 & 55 & 112 \\
Thuringia & 31 & 46 & 95 \\
\hline
\end{tabular}

gery centers in different regions. In Germany, except for Fobi/Capella bypass all bariatric procedures were performed over the last few years (table 6). 


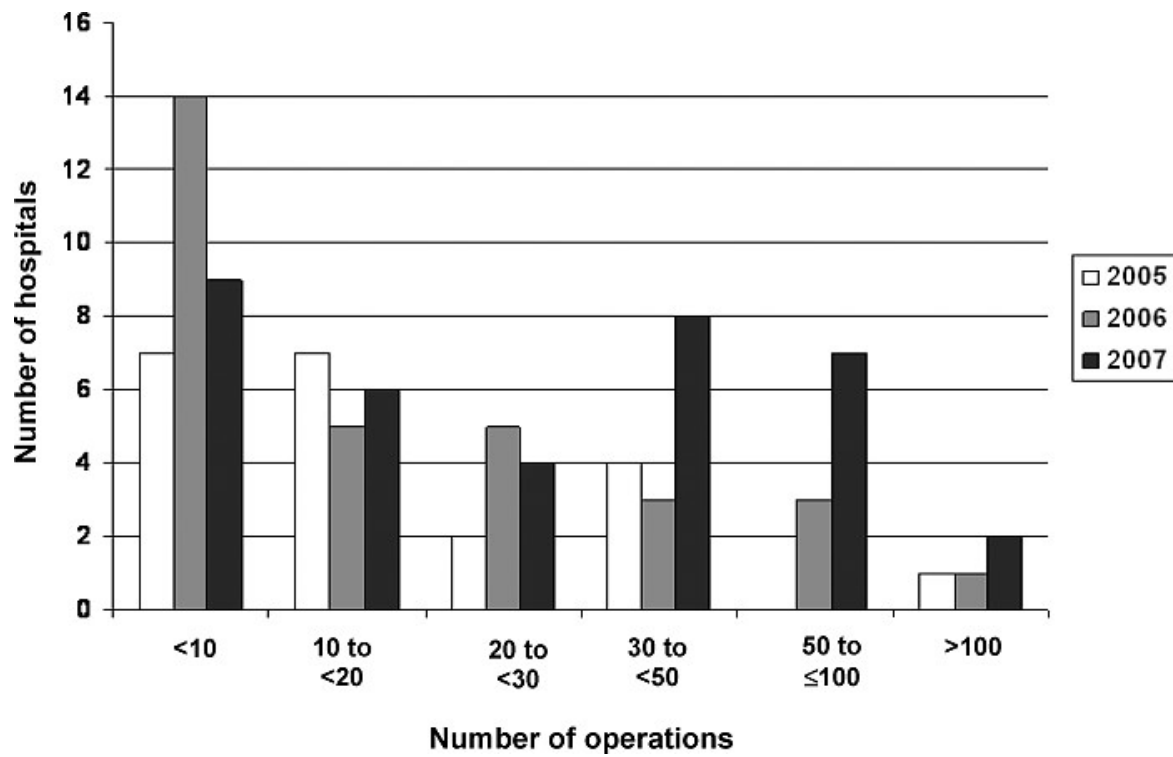

Fig. 2. Distribution of hospitals based on the number of operations in 2005-2007.

Table 3. Demographic data of all patients enrolled in the study

\begin{tabular}{|c|c|c|c|c|c|c|c|c|c|c|c|c|}
\hline \multirow[b]{2}{*}{ Year } & \multicolumn{3}{|c|}{ Mean age, years } & \multicolumn{3}{|c|}{ Mean height, $\mathrm{cm}$} & \multicolumn{3}{|c|}{ Mean body weight, $\mathrm{kg}$} & \multicolumn{3}{|c|}{ Mean BMI, $\mathrm{kg} / \mathrm{m}^{2}$} \\
\hline & 2005 & 2006 & 2007 & 2005 & 2006 & 2007 & 2005 & 2006 & 2007 & 2005 & 2006 & 2007 \\
\hline Men & 42.7 & 44.1 & 42.0 & 180 & 180 & 180 & 160 & 164.7 & 163.7 & 49.4 & 50.8 & 50.5 \\
\hline Women & 39.6 & 40.7 & 40.2 & 167 & 167 & 167 & 134 & 134.6 & 133.0 & 48.2 & 48.5 & 47.7 \\
\hline Total & 40.4 & 41.6 & 40.7 & 170 & 170 & 170 & 141 & 142.3 & 141.1 & 48.5 & 49.1 & 48.5 \\
\hline
\end{tabular}

Table 4. Distribution of comorbidities, $\%$

\begin{tabular}{lrrrr}
\hline & 2005 & 2006 & 2007 & $2005-2007$ \\
\hline No comorbidity & 19.2 & 18.0 & 18.9 & 17.6 \\
Hypertension & 50.2 & 53.0 & 50.1 & 47.9 \\
Cardiac comorbidity & 6.8 & 11.5 & 9.8 & 9.1 \\
IDDM & 9.4 & 9.7 & 7.3 & 7.9 \\
NIDDM & 9.7 & 17.6 & 16.9 & 14.6 \\
Pulmonary comorbidity & 16.4 & 21.5 & 16.0 & 16.6 \\
Pulmonary embolism preoperative & 0.2 & 1.2 & 3.2 & 1.8 \\
Sleep apnea & 14.5 & 14.9 & 16.4 & 14.7 \\
Cholecystolithiasis & 12.7 & 6.6 & 4.7 & 6.5 \\
GERD & 11.8 & 16.6 & 15.6 & 14.2 \\
Varicosis & 4.8 & 7.3 & 6.8 & 6.1 \\
Skeletal diseases & 80.9 & 75.0 & 65.1 & 70.9 \\
\hline
\end{tabular}

IDDM = Insulin-dependent diabetes mellitus; NIDDM = non-insulindependent diabetes mellitus; GERD = gastroesophageal reflux disease.

In comparison with results from a published meta-analysis, bariatric patients in Germany were significantly older (table 7). In addition, BMI was significantly higher and more patients suffered from diabetes and hypertension (table 8) $[9,10]$. This might explain why more RYGBP than GB procedures were performed in 2007. The influence of high BMI and the high rate of comorbidities must be considered when evaluating the data, in particular those obtained in the long-term follow-up investigation of persistent effects on weight reduction and amelioration of comorbidities. After restrictive procedures, the weight loss observed was less than that reported in the literature, and the factors mentioned above have to be taken into account.

German Survey in Bariatric Surgery
The study data obtained between 2005 and 2007 show that there was a tendency to shift from restrictive to more malabsorptive operations. This effect seemed to be influenced by the high preoperative BMI of German patients.

The increasing long-term complications after GB were also detected in the study presented here. The number of required reoperations after GB is increasing. This is reflected in the data obtained for patients who underwent GB before January 1, 2005. According to the data from the literature, the frequency of reoperations increased up to $2 \%$ for each year of follow-up [11].

After SG the frequency of general complications was $14.1 \%$. Leaks occurred in $7 \%$ of the study participants. SG is a high-risk procedure mostly performed as a first step in high-risk patients. In a German trial, 2 patients died after SG and therefore the mortality was $1.6 \%$. The reported mortality rate after SG ranged from $0.0 \%$ to $3.6 \%$ in the literature [12]. The impact of gender, age, BMI, and comorbidities on weight loss has to be evaluated in future studies. Mortality after DS does not differ from mortality after SG in the literature, however, morbidity after SG is much higher than morbidity after DS [12].

The incidence of RML has been reported to range from $0.9 \%$ to $22.7 \%$ [13]. In the present study, the mortality associated with RML was $0.06 \%$.

As this study was based on voluntary participation, it is very likely that the actual mortality is higher than that reported here.

Follow-up data were available for a total of 929 (63.8\%) patients. This means that $28.3 \%$ of the patients were lost to follow-up investigation by 1 year postoperatively, which might be considered as a 


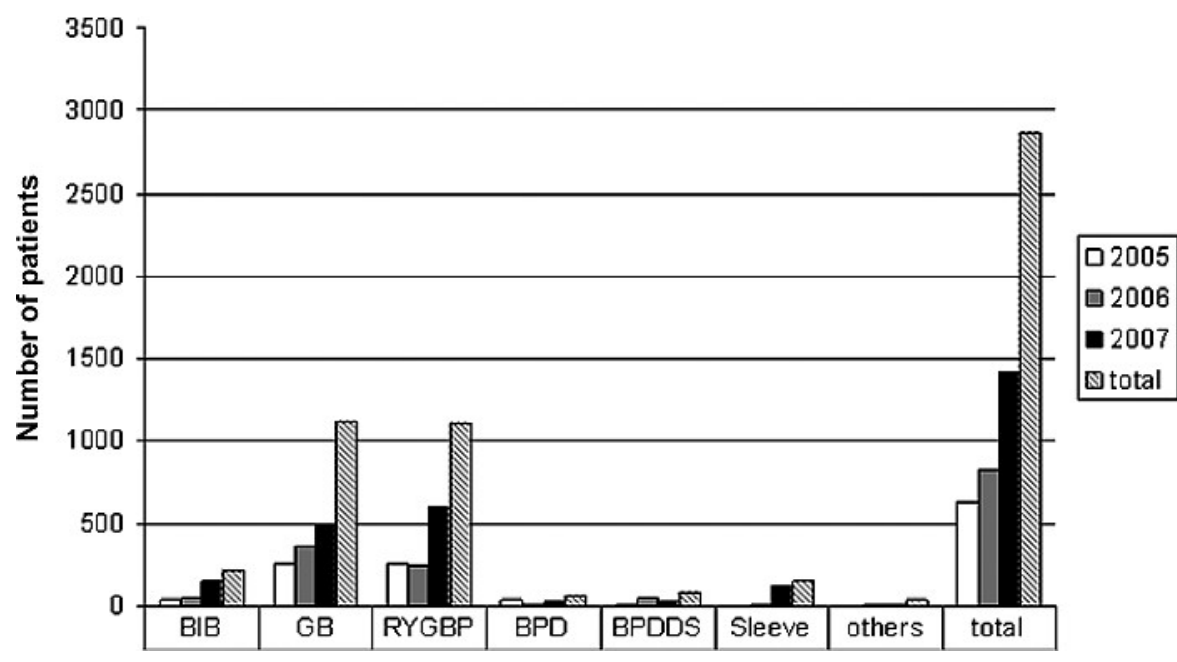

Fig. 3. Distribution of primary surgical interventions and redo operations.

Table 5. Weight reduction dimensions of different procedures

\begin{tabular}{lllll}
\hline & $\begin{array}{l}\text { Number } \\
\text { of patients }\end{array}$ & $\begin{array}{l}\text { Preoperative BMI, } \\
\mathrm{kg} / \mathrm{m}^{2}\end{array}$ & \multicolumn{2}{l}{ BMI reduction, $\mathrm{kg} / \mathrm{m}^{2}$} \\
\cline { 3 - 5 } & 10 & 59.8 & -7.7 & range \\
\hline BIB & 475 & 46.8 & -7.1 & -32 to -1 \\
GB & 359 & 48.2 & -14.0 & -26 to 5 \\
RYGBP & 30 & 53.9 & -16.2 & -32 to 14 \\
BPD & 24 & 53.3 & -18.8 & -40 to -9 \\
DS & 6 & 54.4 & -10.1 & -19 to -6 \\
\hline SG & & &
\end{tabular}

Table 6. Comparison of different studies in obesity surgery

\begin{tabular}{lllll}
\hline & Meta-analysis [10] & Meta-analysis [14] & French trial [15] & German trial [7] \\
\hline Time period & $1990-2002$ & - & $12 / 2002-01 / 2003$ & $01 / 2005-12 / 2007$ \\
Patients, $n$ & 22,094 & 11,314 & 1,236 & 2,869 \\
Performed procedures, \% & & & \\
BIB & & & & 7.8 \\
GB & 24.1 & 49.1 & 87.3 & 40.5 \\
SG & & & & 5.2 \\
VBG & 5.4 & 18.4 & 8.6 & 0.1 \\
RYGBP & 64.1 & 26.0 & 3.8 & 40.4 \\
BPD/BPD-DS & 4.8 & 6.5 & 0.3 & 5.2 \\
Others & & & & 0.8 \\
\hline
\end{tabular}

Table 7. Comparison of age and BMI in German trial [7] to meta-analysis [10]

\begin{tabular}{|c|c|c|c|c|c|c|c|c|}
\hline & \multicolumn{4}{|c|}{ Mean age, years } & \multicolumn{4}{|c|}{ Mean BMI, $\mathrm{kg} / \mathrm{m}^{2}$} \\
\hline & \multicolumn{3}{|c|}{ German trial } & \multirow{2}{*}{$\begin{array}{l}\text { meta- } \\
\text { analysis }\end{array}$} & \multicolumn{3}{|c|}{ German trial } & \multirow{2}{*}{$\begin{array}{l}\text { meta- } \\
\text { analysis }\end{array}$} \\
\hline & 2005 & 2006 & 2007 & & 2005 & 2006 & 2007 & \\
\hline Men & 42.7 & 44.1 & 42.0 & & 49.4 & 50.8 & 50.5 & \\
\hline Women & 39.6 & 40.7 & 40.2 & & 48.2 & 48.5 & 47.7 & \\
\hline Total & 40.4 & 41.6 & 40.7 & 38.97 & 48.5 & 49.1 & 48.5 & 46.8 \\
\hline
\end{tabular}

Table 8. Comparison of comorbidities in the German trial [7] and the meta-analysis [10]

\begin{tabular}{llll}
\hline & Meta-analysis & German trial & Significance, $\mathrm{p}$ \\
\hline Patients, $\mathrm{n}$ & 22,094 & 3,123 & \\
Comorbidities, $\%$ & & & \\
$\quad$ Hypertension & 35.4 & 47.9 & $<0.001$ \\
Cardiac diseases & 7.0 & 9.1 & $<0.001$ \\
Pulmonary diseases & 10.7 & 16.6 & $<0.001$ \\
Diabetes mellitus & 15.3 & 22.5 & $<0.001$ \\
Sleep apnea & 19.6 & 14.7 & $<0.001$ \\
Skeletal diseases & 50.3 & 70.9 & $<0.001$ \\
\hline
\end{tabular}


possible bias in interpreting results on weight reduction and amelioration of comorbidities. According to the literature, weight loss is greater after malabsorptive than after restrictive procedures. Weight reduction data for men and women did not differ significantly during the follow-up investigation periods. Data on amelioration of diabetes were similar to those obtained in a meta-analysis [10]. However, the influence of the type of operation on amelioration of comorbidities was not assessed at that time of analyses $[16,17]$.

Data collection from all or at least the majority of bariatric procedures performed in Germany is necessary to appropriately assess perioperative morbidity and mortality after bariatric surgery as well as to competently characterize patients' outcomes. Therefore, it is recommended that all hospitals performing bariatric surgery participate in the German prospective multicenter trial on quality assurance in bariatric surgery.

\section{Conclusion}

In the German nationwide survey the results regarding bariatric surgery are similar to those published in clinical trials and singlecenter studies. In the literature, no evidence-based recommendations on how to select patients for restrictive or malabsorptive pro- cedures exist. Information on predictive factors for patient selection is necessary to improve patient outcomes and reduce perioperative morbidity.

In the present German multicenter study, follow-up data after only 1 year was collected although life-long follow-up investigations may be required, especially after bariatric malabsorptive procedures. Due to the lack of evidence-based data, this study was initiated to prospectively collect data on bariatric operations performed in Germany. The aim of the quality assurance study is to evaluate the current situation of bariatric surgery in Germany [8].

\section{Acknowledgements}

We thank all colleagues from the participating clinics and hospitals for their active support.

\section{Disclosure}

We thank Johnson and Johnson Medical GmbH as well as Ethicon EndoSurgery Norderstedt for financial support of the German multicenter trial on quality assurance in bariatric surgery. A conflict of interest or any connection to products mentioned in this report does not exist.

\section{References}

1 Mensik GBM, Lampert T, Bergmann E: Übergewicht und Adipositas in Deutschland 1984-2003. Bundesgesundheitsbl Gesundheitsforsch Gesundheitsschutz 2005;48:1348-1356.

2 Benson K, Hartz AJ: A comparison of observational studies and randomized, controlled trials. N Engl J Med 2000;342:1878-1886.

3 Ellis J, Mulligan I, Rowe J, et al: Inpatient general medicine is evidence based. A-Team, Nuffield Department of Clinical Medicine. Lancet 1995;346:407-410.

4 Christou N, Sampalis J, Liberman M, et al: Surgery decreases long-term mortality, morbidity and health care use in morbidly obese patients. Ann Surg 2004;240:416-424.

5 Sjoström L, Lindroos AK, Peltonen M; Swedish Obese Subjects Study Group: Lifestyle, diabetes and cardiovascular risk factors 10 years after bariatric surgery. N Engl J Med 2004;351:2683-2693.

6 Sjöström L, Narbro K, Sjöström CD, et al: Ef fects of bariatric surgery on mortality in Swedish obese subjects. N Engl J Med 2007;357:741-752.

$\checkmark 7$ Stroh C, Birk D, Flade-Kuthe R, Frenken M, Herbig B, Höhne S, Köhler H, Lange V, Ludwig K, Matkowitz R, Meyer G, Meyer F, Pick P, Horbach T, Krause S, Schäfer L, Schlensak M, Shang E, Sonnenberg T, Susewind M, Voigt H, Weiner R, Wolff S, Lippert H, Wolf AM, Schmidt U, Manger T; Bariatric Surgery Working Group: A Nationwide Survey on Bariatric Surgery in Germany - results 2005-2007. Obes Surg 2009;19:105-112.
8 Stroh C, Manger T: Studie zur Qualitätskontrolle der operativen Therapie der Adipositas. Mitt Dtsch Ges Chir 2004;33:389-391.

9 Buchwald H: Consensus conference statement. Bariatric surgery for morbid obesity: Health implications for patients, health professionals, and thirdparty payers. Surg Obes Relat Dis 2005;1:371-381.

10 Buchwald H, Avidor Y, Braunwald E, et al: Bariatric surgery. A systematic review and meta-analysis. JAMA 2004;14:1724-1737.

11 Suter M, Calmes JM, Paroz A, et al: A 10-year experience with laparoscopic gastric banding for morbid obesity: High long-term complication and failure rates. Obes Surg 2006;16:829-835.

12 Clinical Issues Committee of American Society for Metabolic and Bariatric Surgery (ed): Sleeve gastrectomy as a bariatric procedure. Surg Obes Relat Dis 2007;3:573-576.

13 Stroh C, Hohmann U, Remmler K, et al: Rhabdomyolysis after biliopancreatic diversion with duodenal switch. Obes Surg 2005;15:1347-1351.

14 Maggard MA, Shugarman LR, Suttrop M, Maglione M, Sugarman HJ, Livingston EH, Nguyen NT, Li Z, Mojica WA, Hilton L, Rhodes S, Morton SC, Shekelle PG: Meta-analysis. Surgical treatment of morbid obesity. Ann Intern Med 2005;142:547-559.
5 Basdevant A, Paita M, Rodde-Dunet MH, Marty M, Noguès F, Slim K, Chevallier JM: A nationwide survey on bariatric surgery in France: two years prospective follow-up. Obes Surg 2007;17: 39-44.

16 Stroh C, Birk D, Flade-Kuthe R, Frenken M, Herbig B, Höhne S, Köhler H, Lange V, Ludwig K, Matkowitz R, Meyer G, Meyer F, Pick P, Horbach T, Krause S, Schäfer L, Schlensack M, Shang E, Sonnenberg T, Susewind M, Voigt H, Weiner R, Wolff S, Lippert H, Wolf AM, Schmidt U, Manger T: Arbeitsgruppe Adipositaschirurgie. Studie zur Qualitätskontrolle der operativen Therapie der Adipositas - Ergebnisse der Jahre 2005 und 2006. Zentralbl Chir 2008;33: 473-478.

17 Stroh C, Birk D, Flade-Kuthe R, Frenken M, Herbig B, Höhne S, Köhler H, Lange V, Ludwig K, Matkowitz R, Meyer G, Meyer F, Pick P, Horbach T, Krause S, Schäfer L, Schlensak M, Shang E, Sonnenberg T, Susewind M, Voigt H, Weiner R, Wolff S, Lippert H, Wolf AM, Schmidt U, Manger T, Bariatric Surgery Working Group: A nationwide survey on bariatric surgery in Germany - Results 2005-2007. Obes Surg 2009;19:105-112. 